\title{
A compreensão da multiplicação como adição de parcelas iguais por meio de jogo
}

em sala de aula

\section{The understanding of the multiplication as the sum of equal parts through games in classroom}

Lucinéia Barbosa da Silva Secretaria Municipal de Educação (SMED/BH), Belo Horizonte, MG, Brasil (Dhttps://orcid.org/0000-0002-7258-7686, lucineiabs@edu.pbh.gov.br

Samira Zaidan

Universidade Federal de Minas Gerais (UFMG), Faculdade de Educação, Belo Horizonte, MG, Brasil

https://orcid.org/0000-0001-7163-5546, samira@fae.ufmg.br

\section{Informações do Artigo \\ Como citar este artigo \\ SILVA, Lucinéia Barbosa da; ZAIDAN, \\ Samira. A compreensão da multiplicação como adição de parcelas iguais por meio de jogo em sala de aula. REMAT: Revista \\ Eletrônica da Matemática, Bento \\ Gonçalves, RS, v. 7, n. 1, p. e2009, 24 de maio de 2021. DOI: \\ https://doi.org/10.35819/remat2021v7i1id4634}

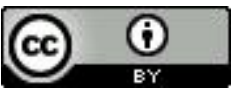

\section{Histórico do Artigo}

Submissão: 2 de outubro de 2020.

Aceite: 18 de fevereiro de 2021.

\section{Palavras-chave}

Multiplicação de Números Naturais

Ensino-Aprendizagem

Educação Matemática

\section{Resumo}

O objetivo principal deste artigo é discutir, com base em uma atividade, como a prática de jogos no ensino pode enriquecer a compreensão e a aprendizagem da multiplicação de números naturais em turmas de $5^{\circ}$ ano do Ensino Fundamental. Buscamos também analisar como as interações de maneira colaborativa nessa ação podem favorecer a aprendizagem dos estudantes. A prática com um jogo foi realizada por meio de uma sequência didática, na proposta da pesquisa-ensino, na qual a pesquisadora investiga a própria prática. Realizou-se um diálogo com os estudantes antes da execução das atividades e, posteriormente, foram explicadas as regras do jogo e desenvolvida a sequência. A reflexão das ações e resultados mostra a existência de compartilhamento de conhecimentos e experiências, o que favoreceu aprendizados de maneira significativa. $O$ uso do jogo evidenciou que a interação propiciada em seu desenvolvimento, leva a uma melhor compreensão da multiplicação como a soma de partes iguais, bem como o entendimento de que a comutatividade estaria vinculada a uma mudança na situação apresentada.

\section{Keywords}

Multiplicacion Natural Numbers

Teaching-Learning

Mathematical Education

\begin{abstract}
The main objective of this article is to discuss, based on an activity, how games can enrich the understanding and learning of the multiplication of Natural Numbers in Elementary School for 5th grade students. We also seek to analyze how interactions can favor students' learning in a collaborative way. The practice with a specific game was carried out through a didactic sequence, in the teaching-research proposal, in which researchers investigate their own practices. A dialogue was held with the classes before the activities were carried out, the rules of the game were previously explained and the sequence was developed. The reflection on actions and results shows the existence of knowledge and experience sharing, which favored learning in a significant way. The use of the game showed that the interaction leads to a better understanding of multiplication as a sum of equal parts, as well as the understanding that commutativity would be linked to a change in the situation presented.
\end{abstract}




\section{Introdução}

$\mathrm{Na}$ busca por proporcionar um aprendizado que torne o estudante sujeito ativo na construção do conhecimento, de forma que amenize as angústias deste diante das operações matemáticas, trabalhamos em nossa pesquisa com atividades que promoveram a interação entre estes sujeitos, de maneira colaborativa. Essas atividades constituíram, assim, costumes e hábitos que favoreceram o aprendizado. De acordo com Lopes (2012, p. 211), esse conjunto de hábitos e costumes estabelecem:

O ethos dos novos letramentos [...] definido por ser colaborativo. É constituído pela ação de pessoas participando/agindo nas práticas de letramentos em conjunto na construção de textos e significados, que são, portanto, menos individualizados e autorais, uma vez que a autoria é colaborativa não sendo dominada por ninguém.

Nesse sentido, de acordo com Nacarato, Mengali e Passos (2011), um ambiente de aprendizagem precisa ser marcado, essencialmente, pela presença do diálogo. A relação dialógica constitui a primeira característica desse ambiente, o que não se resume à troca de ideias, ao contrário, refere-se ao compartilhamento de ideias e saberes, o que instiga as discussões e análises sobre o que os estudantes dizem, de modo que haja comunicação. De acordo com as autoras, essa é uma característica que merece destaque para haver um ambiente propício à aprendizagem.

Deste modo, assim como Cavalcanti (2001), Smole e Diniz (2001) e Conti e Longo (2017), acreditamos que estas práticas escolares - que promovem socialização, trocas e procedimentos de construção de conhecimentos - proporcionam, aos estudantes, oportunidades de serem solidários, colaborativos e capacitados a resolverem situações-problema. Por esse motivo, a sequência didática realizada com os estudantes contemplou as práticas descritas pelas autoras.

$O$ trabalho relatado é parte de uma experiência vivenciada no PROMESTRE ${ }^{1}$, no primeiro semestre de 2019, em que desenvolvemos, em 16 aulas, uma sequência didática composta por nove atividades que contemplaram as quatro ideias da multiplicação de números naturais: adição de parcelas iguais, raciocínio combinatório, configuração retangular e proporcionalidade ${ }^{2}$. Discorreremos ao longo do artigo uma atividade em que o foco foi o entendimento da multiplicação como adição de parcelas iguais, com atenção especial à propriedade comutativa. $\mathrm{O}$ processo de desenvolvimento da pesquisa consistiu em: elaborar e realizar uma sequência didática com 19 estudantes do $5^{\circ}$ ano do Ensino Fundamental, de uma escola municipal em Belo Horizonte/MG, em que uma das autoras era professora; produzir e coletar os dados das atividades desenvolvidas; analisar e discutir os dados obtidos no desenvolvimento da atividade. Deste modo, ao propor esta atividade buscamos responder: Quais contribuições foram observadas ao desenvolver o jogo na compreensão da multiplicação de números naturais?

\footnotetext{
1 PROMESTRE é o Programa de Pós-Graduação Stricto Sensu do Mestrado Profissional em Educação e Docência da Faculdade de Educação da UFMG.

2 Tais ideias serão abordadas mais adiante, nos pressupostos teóricos.
} 
A atividade, descrita mais adiante, durou quatro aulas, sendo executada em dois dias. Nela, buscamos desenvolver a ideia da multiplicação ao calcular a quantidade de pulos que uma "bota" executaria em um tabuleiro montado na quadra da escola, no intuito de trabalhar o entendimento de adição de parcelas iguais, com ações compartilhadas, pois foi realizada de maneira coletiva. Isto é, considerávamos que a organização dos estudantes em grupo promoveria a melhor capacidade de resolução de problemas e atividades, uma vez que figuraria o compartilhamento de informações, de modo a propiciar e mobilizar novos saberes, o que favoreceria, assim, a comunicação e estimulação da aprendizagem dos mesmos (SMOLE; DINIZ, 2001).

O texto está estruturado da seguinte forma: na Seção 2 expomos os pressupostos teóricos que fundamentaram a proposta; na Seção 3 escrevemos sobre o jogo interativo na proposta da pesquisa-ensino e apresentamos o que é necessário para desenvolver a atividade; na Seção 4 detalhamos o desenvolvimento da atividade; na Seção 5 problematizamos e discutimos seus desdobramentos e encerramos com as considerações finais e as referências.

\section{Referencial teórico}

De acordo com Ramos (2009), quando uma criança questiona o professor ou a professora se a operação a ser feita em determinado problema é "de mais ou de menos", é porque ela ainda não percebe a necessidade de refletir sobre a ação que precisa ser feita para transformar uma situação inicial. Nesse sentido, Conti e Longo (2017) atentam para o tipo de atividades que são propostas aos estudantes, pois, se estão acostumados a resolver operações, sejam elas de adição, subtração, multiplicação ou divisão, de maneira descontextualizada, apresentarão dificuldades ao resolverem situações-problema.

Entendemos que usualmente as atividades requerem apenas o uso de operações matemáticas, como em exercícios de "arme e efetue", o que pode levar o estudante a ter dificuldade ao se deparar com a necessidade de interpretar situações-problema, que precisariam ser transformadas, uma vez que as operações não são explicitamente apresentadas. Isso explica a necessidade que muitas crianças têm de perguntar qual é a operação adequada. As autoras Conti e Longo (2017) afirmam que todos nós resolvemos problemas diariamente e que da mesma forma buscamos recursos para solucioná-los, por isso é importante que a proposta feita aos estudantes também propicie a busca por mecanismos que os direcionem à solução adequada e garanta a apropriação do conhecimento envolvido.

Assim, podemos questionar, em relação as nossas práticas, uma tendência a buscar respostas imediatas dos estudantes, muitas vezes elaboradas sem esforço cognitivo. Essa preocupação nos levou a desenvolver atividades que interrogassem e que provocassem o diálogo durante a interação promovida pelo jogo, o que poderia propiciar, desse modo, a construção de um ambiente de aprendizagem colaborativo e a compreensão da multiplicação. 
De acordo com os estudos realizados por Moreira e David (2007), tem sido comum os estudantes apresentarem dificuldades em questões como identificar o valor posicional dos algarismos no Ensino Fundamental, assim como a permanência, nos anos seguintes, das dificuldades em realizar operações como a subtração, por exemplo. Isso demonstra a complexidade que envolve os números naturais e suas características, bem como as relações estabelecidas entre eles. Esses autores evidenciam as dificuldades desenvolvidas pelos estudantes, apresentando pesquisas realizadas com crianças inglesas na mesma faixa etária que, no Brasil, corresponde ao Ensino Fundamental. Os autores constatam a existência de inúmeras pesquisas empíricas evidenciando que compreender com clareza o Sistema de Numeração Decimal é um processo longo desenvolvido durante todo o Ensino Fundamental, além de revelar que isto se constitui como um dos aspectos mais complexos da aprendizagem relacionada aos números (DICKSON et al., 1993, apud MOREIRA; DAVID, 2007).

Pelo que foi observado por Moreira e David (2007), Ramos (2009) e Conti e Longo (2017), constatamos a complexidade que envolve a aprendizagem dos números naturais, que são a base para a compreensão dos números e cálculos na Matemática. Deste modo, entender de maneira adequada as características dos números naturais e do Sistema de Numeração Decimal não é algo tão simples como pode parecer, bem como a aprendizagem parcial pode levar a dificuldades na compreensão das operações matemáticas. Nessa perspectiva, Carraher $(1994$, p. 66) alerta que "a escola tenta sistematizar estas regras para que a criança resolva com lápis e papel operações que ela deveria compreender e resolver mentalmente antes de preocupar-se com o lápis e o papel". Por isso, ressalta-se que o trabalho realizado busque a compreensão dos esquemas de ação envolvidos nas operações, de maneira que o estudante seja motivado e encorajado a encontrar as soluções adequadas, construindo suas aprendizagens, significativamente.

Desse modo, cabe ao professor o trabalho com o ensino de operações envolvendo propostas metodológicas diversificadas e diferenciadas, como a manipulação de materiais didáticos, especificamente como o BASE DEZ (material dourado) que trabalha para se realizar grandes contagens e possibilita a compreensão do sistema de numeração. Já para a compreensão da multiplicação buscamos fundamentação em Caraça (1998), que apresenta um melhor entendimento da complementação dos princípios aditivo e multiplicativo ${ }^{3}$, pois passa a trabalhar a adição de parcelas iguais pela ideia de multiplicação, facilitando assim o processo de resolução.

Apesar de a ideia da adição de parcelas iguais ser a mais difundida, nos últimos anos têmse lançado algumas controvérsias com relação a isso, pois, se considerarmos, como ponto de partida, o pressuposto conceitual, há uma diferença relevante entre multiplicação e adição.

\footnotetext{
${ }^{3}$ No princípio aditivo a premissa básica é a relação parte-todo. No princípio multiplicativo é a relação fixa entre duas variáveis. Mais adiante há uma melhor exploração sobre esses aspectos, com exemplos que facilitam a compreensão.
} 
Carraher et al. (2005) atentam para o fato de que, na adição, a premissa básica é que o todo é igual à soma das partes, ou seja, esse é um fundamento principal do raciocínio aditivo, a relação parte-todo.

Em contraste, o invariante conceitual do raciocínio multiplicativo é a existência de uma relação fixa entre duas variáveis (ou duas grandezas ou quantidades). Qualquer situação multiplicativa envolve duas quantidades em relação constante entre si (CARRAHER et al., 2005, p. 85).

Pode-se exemplificar o excerto acima com a situação: Carla convidou 4 amigas para um lanche e quer presentear cada uma delas com 3 brigadeiros. Quantos brigadeiros ela precisa fazer? Observamos nessa situação que as variáveis são o número de amigas e o número de brigadeiros, em que a relação estabelecida é a proporção de três doces para cada uma das amigas. Identificar tais relações permite que a criança compreenda a ideia envolvida e busque soluções adequadas.

De acordo com os autores, a diferença entre os raciocínios aditivo e multiplicativo está centrada no seguinte: ao resolvermos um problema que trabalha a adição, partimos sempre da relação parte-todo. Isto é, temos (n) partes iguais que se juntarão para formar um todo. Já nos problemas que envolvem a multiplicação, buscamos "um valor numa variável que corresponda a um valor dado na outra variável" (CARRAHER et al., 2005, p. 85), ou seja, um valor fixo transforma outro valor variável. Por exemplo: a adição de 5 parcelas de 17 objetos, pode ser assim indicada: $17+17+17+17+17=5 \times 17$. Vemos que, na adição de parcelas iguais, as partes se mostram para serem reunidas; na multiplicação, temos duas variáveis em relação, uma de valor fixo que vai alterar a outra em que o valor se torna variável com base na relação estabelecida entre elas, como mostra o exemplo.

Ramos (2009, p. 79) esclarece essa diferença sutil ao afirmar que, "a multiplicação, em seu aspecto aditivo, lida com números de natureza diferente: um dos números conta grupos e o outro conta quantos são os elementos do grupo", ou seja, quando falamos que $5 \times 17$ é a mesma coisa que 17 × 5 (propriedade comutativa da multiplicação), estamos nos referindo ao resultado, que não se altera, entretanto, é diferente a relação número de grupos e quantidade de elementos por grupo. Portanto, cabe ao professor ampliar o saber da criança para a comutatividade no princípio multiplicativo. Os jogos poderiam induzir a essa nova representação matemática, de modo a desmistificar o que ainda não é compreensível para a criança, uma vez que, no exemplo, o número de grupos e a quantidade em cada grupo foi alterada apesar de formar o mesmo todo.

Atentar-se para esse aspecto e relacioná-lo à comutatividade da multiplicação faz-se necessário em nossas práticas cotidianas com os estudantes, uma vez que é comum fixar a ideia que a ordem dos fatores não altera o produto. Realmente, o resultado não é alterado, mas transforma a compreensão matemática da situação, pois, a criança passará a compreender (17 X $5)=(5 \times 17)$, sem guardar a relação correta estabelecida no raciocínio aditivo, no qual 5 grupos 
de 17 têm uma representação diferente de 17 grupos de 5. Essa compreensão precisa ser melhor trabalhada com a criança.

Carraher et al. (2005) acrescentam que a multiplicação apresenta um aspecto distributivo com relação à adição, como no exemplo: Dona Maria vende balas na porta da escola. Ela precisa organizar 35 pacotinhos com 6 balas em cada. De quantas balas ela precisa? Neste problema, o número de balas em cada pacote e o número de pacotes desejado já estão dados e, assim, resta saber quantas balas serão necessárias para esta condição. Tanto nessa quanto em outras situações em que há a ideia aditiva de multiplicar, pensamos em certa quantidade de grupos com a mesma quantidade de elementos em cada um deles. Ao descobrir o total, que aqui são 210 balas, fica mais fácil perceber que esse total foi distribuído igualmente em 35 pacotinhos.

Como dito anteriormente, a pesquisa de mestrado abordou a multiplicação a partir de quatro perspectivas. Ainda que neste artigo nos debrucemos sobre a ideia da multiplicação como soma de parcelas iguais, é importante lançar luz, mesmo que brevemente, sobre as outras abordagens. Nesse sentido, observamos, em Ramos (2009), que além da ideia central da multiplicação estar relacionada à quantidade de grupos e de elementos nos grupos, o que traduz a ideia aditiva, a multiplicação também pode ser tratada em seu aspecto combinatório e, ainda, na configuração retangular ou multiplicação em linhas e colunas.

O aspecto combinatório, de acordo com Bigode e Frant (2011), é pouco explorado no Ensino Fundamental, pois os estudantes são acostumados a resolver situações mais diretas, relacionadas à adição de parcelas iguais, por isso a importância de propor situações-problema que envolvam essa ideia. Os autores ponderam que ao se depararem com problemas, envolvendo o raciocínio combinatório, como no exemplo: Milena vai à uma festa com as amigas e está em dúvida sobre o que vestir. Ela colocou em sua cama 4 blusas e 3 saias para escolher. Quantas combinações diferentes Milena pode fazer? As crianças começam a resolver sem uma organização determinada e, em muitos casos esquecem ou repetem combinações. Para melhorar isto, recomendam o uso de tabelas ou de diagramas de árvore, que ajudam a organizar o pensamento.

A configuração retangular, também chamada de multiplicação em linhas e colunas, favorece o trabalho com produto de medidas ao ser realizada em matrizes, pois ao delimitar o espaço representado por meio de uma multiplicação referimo-nos à área, ou seja, adquire uma percepção geométrica (BIGODE; GIMENEZ, 2009). Essa ideia permite também trazer aspectos da realidade para a vida dos estudantes, por exemplo, o cálculo da quantidade de cerâmicas necessárias para cobrir determinada superfície; quantos estudantes cabem em uma sala de aula, observando a disposição das carteiras sem ter de contá-las uma a uma.

Por fim, na abordagem a partir da proporcionalidade percebe-se uma relação com a ideia de correspondências, por exemplo, se pensarmos na situação: "se 3 pacotes de figurinhas custam $\mathrm{R} \$ 2,00$, quanto custam 6 pacotes?” (BIGODE; FRANT, 2011, p. 61). É possível que as crianças 
pensem em multiplicar os três pacotes de figurinhas por $R \$ 2,00$, porém é necessário atentar-se para a relação de proporcionalidade estabelecida na situação: cada três pacotes custam $R \$ 2,00$, ou seja, cada grupo com três pacotes corresponde ao valor de $\mathrm{R} \$ 2,00$, sendo assim, seis pacotes custam então, $\mathrm{R} \$ 4,00$.

Diante do quadro teórico discutido, compreendemos que não é necessário que o estudante saiba primeiro a adição e subtração e, depois, multiplicação e divisão, pois, como ideias, já estão, socialmente, inseridas. Muitas vezes, dedicamos mais tempo ao sistema de numeração em si, focando nas operações de adição/subtração, e deixamos a multiplicação/divisão em segundo plano. Talvez possamos raciocinar, de modo mais consistente, que o estudo das ideias das operações desde a infância - e quando possível, analisar as quatro operações básicas ao mesmo tempo - favoreça melhor sua compreensão e do próprio Sistema de Numeração Decimal.

\section{Um jogo interativo para aprender multiplicação na proposta da pesquisa-ensino}

Buscamos vários materiais didáticos para compor uma sequência didática, que foi desenvolvida com estudantes do $5^{\circ}$ ano do Ensino Fundamental, e julgamos pertinente utilizar um jogo encontrado nos cadernos de formação do Pacto Nacional pela Alfabetização na Idade Certa (PNAIC) ${ }^{4}$, intitulado "A bota de muitas léguas". O grupo de estudantes que participou da atividade a que se refere este artigo apresentava muitas dificuldades na compreensão da multiplicação, por isso a escolhemos, elaborando uma adaptação na atividade apresentada pelo PNAIC.

Apoiamo-nos em Penteado e Garrido (2010) que propõem a "pesquisa-ensino", meio pelo qual o pesquisador realiza a investigação em sua própria prática. Essa proposta valoriza o professor como produtor de conhecimento em processos articulados com a universidade. No entanto, as autoras ressaltam a necessidade de estabelecer procedimentos para validar os resultados, especificamente buscando fontes diferenciadas de dados para uma análise teórica.

A modalidade pesquisa-ensino colaborativa se dá quando os professores contam com a ajuda sistemática de pesquisadores que tornam parceiros do processo de investigação e mudança das práticas docentes. A parceria entre a instituição de Ensino Básico e a Universidade ocorre por iniciativa da própria escola, que busca apoio acadêmico para a realização de seus propósitos de inovação, assim como para o desenvolvimento profissional de seus docentes; ou por iniciativa da universidade, que procura aproximar-se mais da escola básica, disponibilizando participação em seus processos investigativos do ensino-aprendizagem, com a elaboração conjunta de projetos (PENTEADO; GARRIDO, 2010, p. 11-12).

Tivemos o apoio de uma pesquisadora auxiliar para fazer o registro em diário de campo, quando da realização das aulas para o desenvolvimento da proposta, já que a primeira autora

\footnotetext{
${ }^{4}$ O Pacto Nacional pela Alfabetização na Idade Certa foi um programa de formação continuada oferecido pelo Governo Federal, em parceria com estados e municípios, aos professores dos anos iniciais $\left(1^{\circ}\right.$ ao $\left.3^{\circ}\right)$ do Ensino Fundamental de todas as escolas municipais e estaduais do Brasil, visando a alfabetização das crianças nessas faixas etárias em Língua Portuguesa e Matemática. Essa formação foi realizada de 2013 a $2015 \mathrm{com}$ um grande investimento em materiais e recursos pedagógicos para os professores e as escolas, além de um incentivo por meio de bolsa no valor de $R \$ 200,00$ para cada professor cursista e $R \$ 765,00$ para cada professor Orientador de Estudos.
} 
deste texto, como professora e pesquisadora, era a responsável pelo desenvolvimento da aula. Além disso, contamos também com fotografias dos registros das atividades nos cadernos dos estudantes e a gravação em áudio das opiniões emitidas por eles, em um momento de avaliação do que foi desenvolvido.

$\mathrm{Na}$ descrição e na análise do desenvolvimento do jogo a seguir, quando houver diálogos, PP refere-se à professora pesquisadora; nomeamos todos os estudantes como $\mathrm{E}$, seguido de um número (E1 até $\mathrm{E} 19)$.

\subsection{A bota de muitas léguas 5}

\section{Material:}

- Folhas com várias semirretas numéricas, com marcações do zero ao 25.

- Dois conjuntos de cartões numerados e coloridos (5 cartões azuis e 5 cartões amarelos).

- Um desenho de uma semirreta graduada no chão, do zero ao 25 ou uma faixa de papel com a mesma graduação. Na experiência realizada, foi melhor utilizar uma faixa de papel, numerada do zero ao 25 , com $10 \mathrm{~cm}$ de distância entre os números. A Figura 1 e Figura 2 permitem a visualização da faixa de papel.

Figura 1 - Marco inicial de saída no jogo representado na reta.

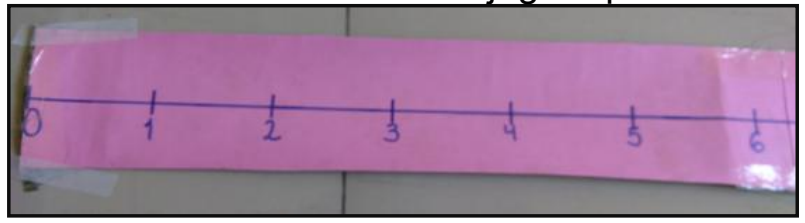

Fonte: Material da pesquisa (2019).

Figura 2 - Local de marcação para atingir o fim do jogo na reta.

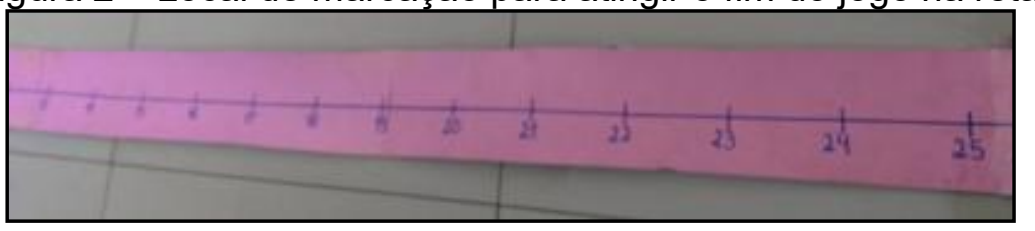

Fonte: Material da pesquisa (2019).

Número de jogadores: todos os estudantes da turma.

\section{Regras (conforme apresentada aos estudantes):}

- Os cartões amarelos indicam a quantidade de pulos que a bota realizará e os cartões azuis, o comprimento dos pulos.

- Defina o número de rodadas para que, assim, seja definido o número de estudantes participantes no sorteio dos cartões e nos "pulos" realizados pela bota imaginária.

\footnotetext{
${ }^{5}$ Este jogo foi adaptado de Brasil (2014), originalmente parte do livro Brasil (2007).
} 
- O participante deverá sortear um cartão numerado amarelo. O número sorteado indica o número de pulos que a "bota" executará. Depois, deverá sortear outro cartão numerado de cor azul. O número indica o comprimento de cada pulo.

Vence o jogo a equipe que, ao final das rodadas, tiver maior saldo de jogadas em que a bota saltou mais longe.

\section{Desenvolvimento da atividade}

Ao iniciar a atividade, houve surpresa com relação ao seu nome; a pesquisadora perguntou se sabiam o que era "léguas" e um dos estudantes relatou que já havia ouvido a expressão "vinte mil léguas submarinas"; outro complementou que a palavra "submarina" significava bem no fundo do mar. Ao serem questionados da diferença entre 20 e 20.000 léguas um dos estudantes respondeu que o primeiro seria mais raso e o outro mais profundo.

Explicou-se que "légua" é uma unidade de medida muito usada antigamente e que seu valor não é exato, por isso houve muitas mudanças no sistema de medidas até chegarmos às medidas chamadas universais. Também foi esclarecido que para realizar a atividade seria utilizada uma reta numérica para medir.

Questionou-se, então, onde poderiam ser encontradas semirretas numéricas, o que levou a menção de réguas, do metro articulado, da trena e a fita para costurar, o que gerou uma discussão acerca da utilidade destes instrumentos. Em seguida, mencionou-se que a régua, por exemplo, tem começo e fim, mas então, quando acabariam os números? Diante desse questionamento e, em meio à conversa sobre a utilidade de cada um desses instrumentos, os estudantes responderam que os números são infinitos.

A professora pesquisadora conduziu a discussão até concluírem que uma régua é um segmento de reta. Explicou como seria a brincadeira e professores e estudantes se dirigiram até a quadra esportiva da escola para a sua realização. Na quadra aberta da escola a tira de papel numerada foi colocada no chão e cartazes foram afixados na parede para registrar as jogadas. $\mathrm{Na}$ primeira jogada, realizada com toda a turma, as fichas sorteadas foram 5 (amarela) e 3 (azul), os estudantes responderam:

- São cinco pulos de três distâncias, então, a bota vai parar no 15.

$\mathrm{Na}$ segunda jogada, inverteram-se as fichas, saíram 3 (amarela) e 5 (azul); rapidamente, os estudantes comentaram:

- Ah, é igual. Vai parar no mesmo lugar.

Os estudantes foram questionados se era realmente a mesma coisa e, após o participante dar os pulos, seu colega E17 explicou:

- O resultado é o mesmo, mas o número e o tamanho dos pulos são diferentes.

O comentário do estudante já demonstra que apesar de termos o mesmo resultado na tarefa, as situações recebem representações matemáticas com modelagem diferentes. 
Figura 3 - Jogadas da turma.

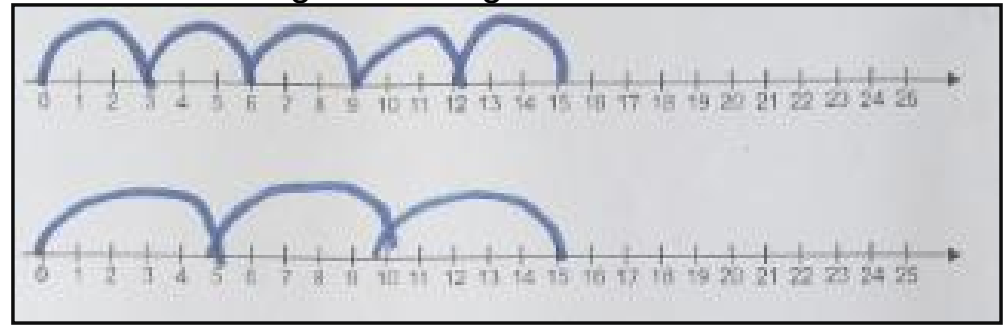

Fonte: Material da pesquisa (2019).

Após o fim das rodadas com a turma, a proposta foi dividi-la em dois grupos. Com $21^{6}$ estudantes, foi-se questionado sobre como realizar a divisão destes em duas equipes. Mencionouse a possibilidade de divisão em partes iguais, porém, a professora pesquisadora insistiu que seriam duas equipes. Um dos estudantes disse que seria 10,5 para cada. Diante dessa fala importante, a professora pesquisadora perguntou como isso seria feito e comparou com um bolo cortado em 21 pedaços que, para ficar igual seriam 10 pedaços para cada lado e sobraria um. Ela perguntou então se poderiam dividir esse pedaço em dois, metade para um e metade para outro, no que os estudantes concordaram que resultaria em 10,5 para cada. A pesquisadora, então, perguntou se isso poderia ser feito com pessoa. Os estudantes concluíram que não seria possível realizar a mesma divisão com grupos de pessoas, de modo que uma equipe ficaria com 10 estudantes (Equipe A) e a outra com 11 (Equipe B).

$\mathrm{Na}$ primeira rodada, as duas equipes sortearam as fichas 2 (amarela) e 2 (azul). Não demonstraram emoção e suspense, pois a bota não iria muito longe. Os estudantes esperavam um número maior para já saírem na frente.

Já na segunda rodada, a Equipe A sorteou 2 (amarela) e 4 (azul), logo disseram que eram dois pulos de quatro distâncias. A Equipe B sorteou 1(amarela) e 3 (azul). Questionados, os estudantes disseram que seria apenas um pulo de três distâncias.

$\mathrm{Na}$ terceira rodada, a Equipe A sorteou 5 (amarela) e 4 (azul). Questionados, explicaram que pararia no 20 , porque $5 \times 4=20$. O estudante foi saltando de 4 em 4 à medida que os colegas falavam os números em que ele deveria parar. A Equipe B sorteou 5 (amarela) e 3 (azul). Questionados sobre o lugar onde iria parar, o estudante E18 respondeu:

- Vai parar no 15. São pulos de três em três.

$\mathrm{Na}$ quarta rodada, a Equipe A sorteou 5 (amarela) e 3 (azul). O participante deu pulos de 3 em 3, e a Equipe B sorteou 1(amarela) e 3 (azul). Perguntados sobre qual equipe venceu, todos identificaram a Equipe A como vencedora.

Todas as rodadas foram registradas em um cartaz, como se pode ver na Figura 4, para facilitar a visualização dos estudantes e ajudar no registro individual, que foi colado no caderno.

\footnotetext{
${ }^{6}$ Todos os estudantes da turma participaram da atividade, porém 19 foram devidamente autorizados a participar da pesquisa.
} 
Figura 4 - Registro das jogadas das equipes.

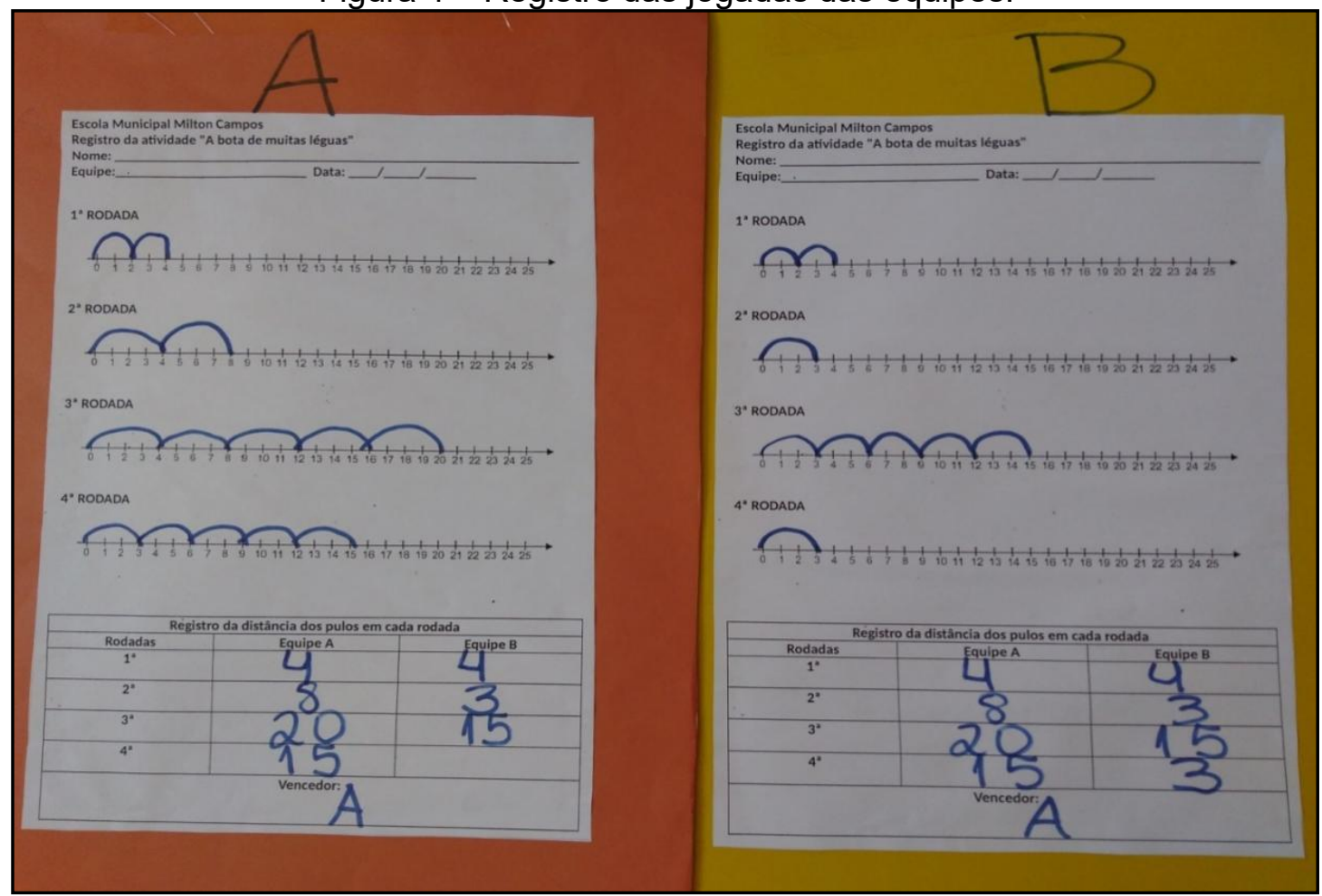

Fonte: Material da pesquisa (2019).

Com relação aos registros realizados pelos estudantes, apenas uma criança apresentou dificuldade. Como se pode constatar na Figura 5, a estudante E10 não observou que o intervalo, na $3^{a}$ rodada, era de três em três, até chegar ao número 15 , considerando que a equipe tinha sorteado as fichas 5 (amarela) e 3 (azul), indicando, assim, cinco pulos de três distâncias. A estudante registrou o resultado da $3^{a}$ rodada como um grande passo, ou seja, um único pulo de 15 distâncias, o que pode indicar uma dificuldade na compreensão acerca do uso da multiplicação em um jogo.

Figura 5 - Registro da estudante E10, Equipe B.

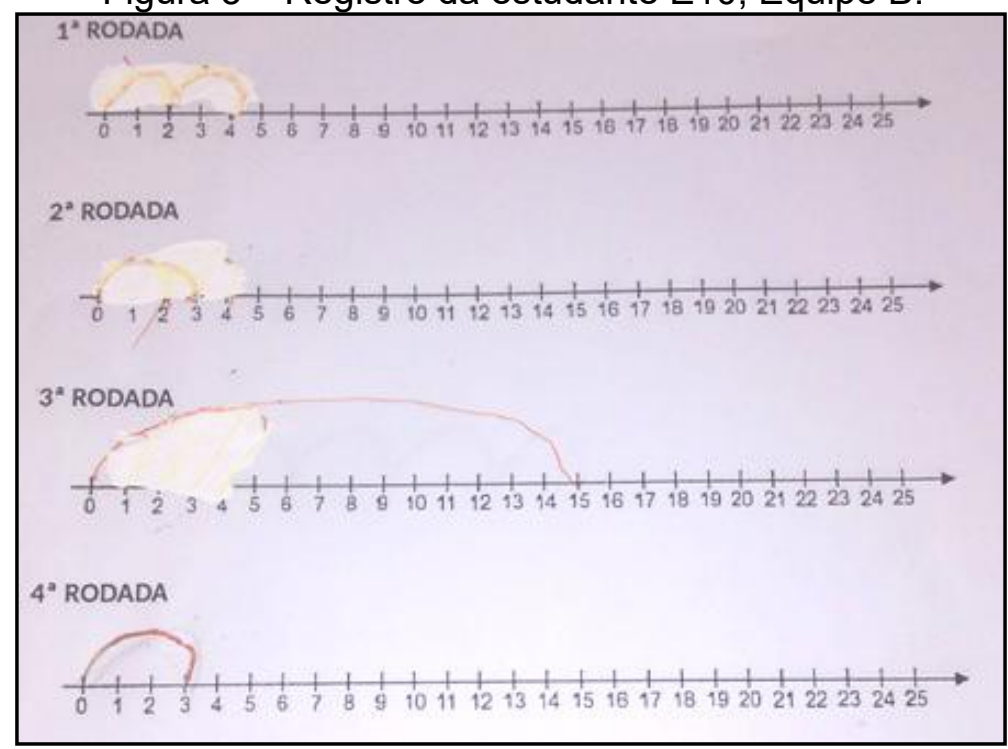

Fonte: Material da pesquisa (2019). 
A discussão da presença do zero na reta numérica foi instigada pelo fato de a reta começar no zero e não em um. Tal discussão foi ampliada para toda a turma, de modo que se observou o seguinte diálogo:

- Para contar as coisas, a gente não pode começar do zero, por exemplo, se eu contar meus dedos e começar do zero quando chegar no último será nove e não dez, vai faltar dedo. (E8)

- O zero não existe. (E5)

- Não existe? (PP)

- Existe, mas não conta. Então, é como se não existisse. (E5)

- Será que não conta? (PP)

Nesse momento, o estudante E14 respondeu:

- Aqui, começa do zero porque temos que medir a distância dele até o número sorteado.

É possível observar que, na concepção dos estudantes, o zero não é necessário para realizar contagens uma vez que a primeira quantidade deve ser um. Na situação em questão, em que se desejava medir distâncias, buscamos observar que a referência era o espaço entre o zero e o número determinado pelo sorteio das fichas. Essa discussão também possibilitou a abordagem da invenção do zero, criado para ocupar ordens vazias no sistema de numeração decimal.

$\mathrm{Na}$ aula seguinte foi realizada uma atividade de exploração desse jogo, como mostra a Figura 6.

Figura 6 - Atividade de exploração do jogo.

1-Observe os cartões que foram sorteados pelas equipes $\mathrm{A}$ e $\mathrm{B}$ :

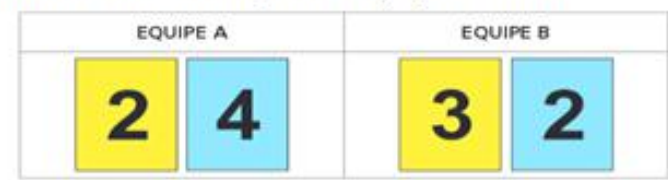

Lembre-se: ficha amarela (número de pulos) e ficha azul (comprimento dos pulos)

2- Registre os pulos realizados pela equipe $A$.

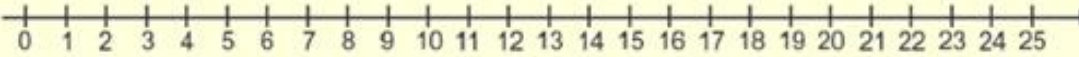

3- Registre os pulos realizados pela equipe $B$.

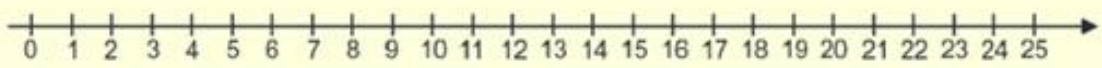

4-Agora, responda: qual das duas equipes, a bota levou para mais longe?

Fonte: Material da pesquisa (2019).

A aula iniciou-se com a devolução do registro da atividade anterior, momento em que a pesquisadora sinalizou para os estudantes o que precisaria ser modificado, como por exemplo, a correção dos pulos realizados de maneira inadequada. Em seguida, a turma foi organizada em 
duplas, dadas as devidas explicações aos que faltaram, para, então, dar início às atividades do dia.

Os estudantes fizeram o registro na folha, de acordo com o que foi efetuado no quadro. Perguntados sobre qual equipe foi "mais longe" com a bota, no item quatro da atividade, todos responderam "Equipe A". Diante disso, os estudantes não apresentaram dificuldade nos quatro primeiros itens da atividade. Rapidamente, visualizaram e verbalizaram como ficariam os pulos na reta numérica.

Figura 7 - Item 5 da Atividade de exploração do jogo.

\begin{tabular}{|c|c|c|c|}
\hline & Número de pulos & Comprimento do pulo & Distância \\
\hline $1^{\mathrm{a}}$ jogada & 5 & 2 & \\
\hline $2^{a}$ jogada & 4 & & 12 \\
\hline $3^{a}$ jogada & & 4 & 20 \\
\hline $4^{\mathrm{a}}$ jogada & 3 & & 18 \\
\hline
\end{tabular}

Fonte: Material da pesquisa (2019).

Em seguida, os estudantes realizaram o item cinco, corrigido posteriormente, de acordo com cada situação - ora número de pulos, ora tamanho do pulo e ora a distância percorrida. A primeira jogada ocorreu de acordo com o esperado, os estudantes falaram logo que a distância era 10; na segunda, foram registradas, na linha numérica traçada no quadro, as diferentes hipóteses relatadas pelos estudantes: de um em um; de dois em dois; de três em três; de quatro em quatro. Dessa forma, perceberam que a situação se referia a quatro pulos de três distâncias.

Na terceira jogada, o estudante E19 disse:

- Se o comprimento do pulo é 4, então o número de pulos é 5 , porque $5 \times 4=20$.

A professora pesquisadora, então, perguntou se todos concordavam com a fala do colega e todos disseram que sim. Efetuou-se o registro de acordo com a orientação fornecida pelo estudante, e a quarta jogada foi respondida da mesma forma.

Figura 8 - Item 6 da Atividade de exploração do jogo.

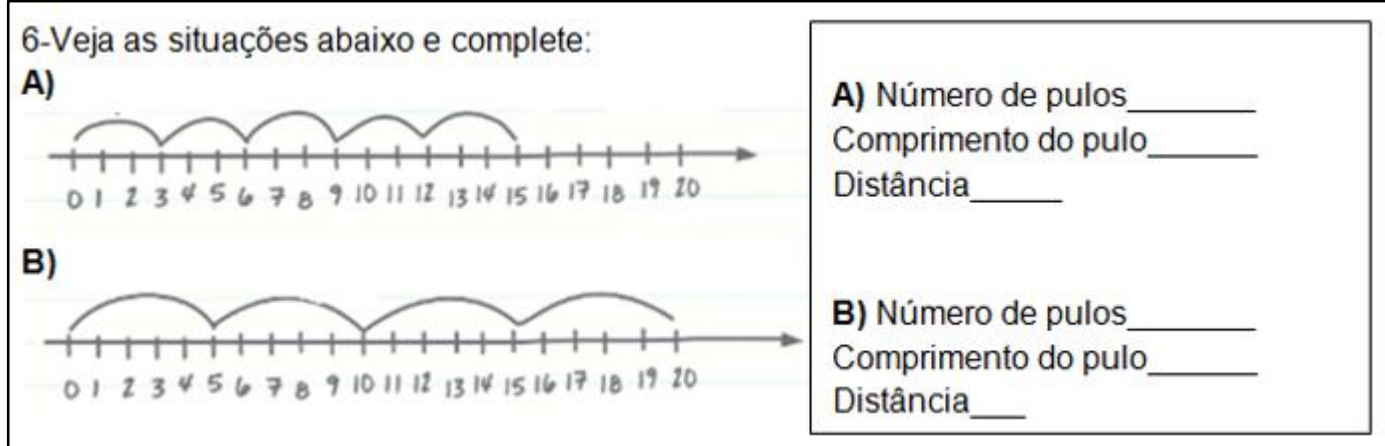

Fonte: Material da pesquisa (2019).

Os estudantes realizaram o item seis de acordo com o registro nas retas numéricas, nas quais o número de "curvas" indicava a quantidade de pulos. Era importante, também, observar a 
distância dos pulos. Um dos estudantes que não vivenciou o jogo, na aula anterior, teve dificuldade em entender que cada curva representava um pulo, por isso houve a necessidade de explicar novamente, com a exibição das fichas e a retomada de seus significados.

A estudante E10 disse que estava com dificuldade em saber o tamanho do pulo; então, foi demonstrado no quadro que a distância do pulo poderia ser verificada na distância do primeiro pulo: do zero até o número marcado pelo primeiro pulo. Para facilitar o entendimento da estudante, desenhou-se uma reta no quadro com as mesmas marcações do exercício. Com a representação no quadro, utilizou-se pincel colorido para numerar os pulos (as curvas) e marcar a distância entre eles, colorindo os espaços entre os números, pois assim, ficaria melhor para o entendimento da estudante. Porém, ao ter contato com a sua atividade, ficou claro que ela não compreendeu o que era pulo e o que era distância, fato que confirmou a hipótese de que realmente estava com dificuldade em compreender a aplicação da multiplicação em um jogo, como foi sinalizado na Figura 5. Ela inverteu os fatores, como se pode ver na Figura 9.

As atividades foram recolhidas, corrigidas e devolvidas na aula seguinte, momento em que a professora pesquisadora pôde mostrar à estudante E10 a troca dos números e explicar, novamente, a diferença entre número de pulos e comprimento dos pulos, com atenção para a importância da compreensão da transformação das situações em que os fatores são os mesmos, mas referem-se a situações distintas.

Figura 9 - Registro da estudante E10.

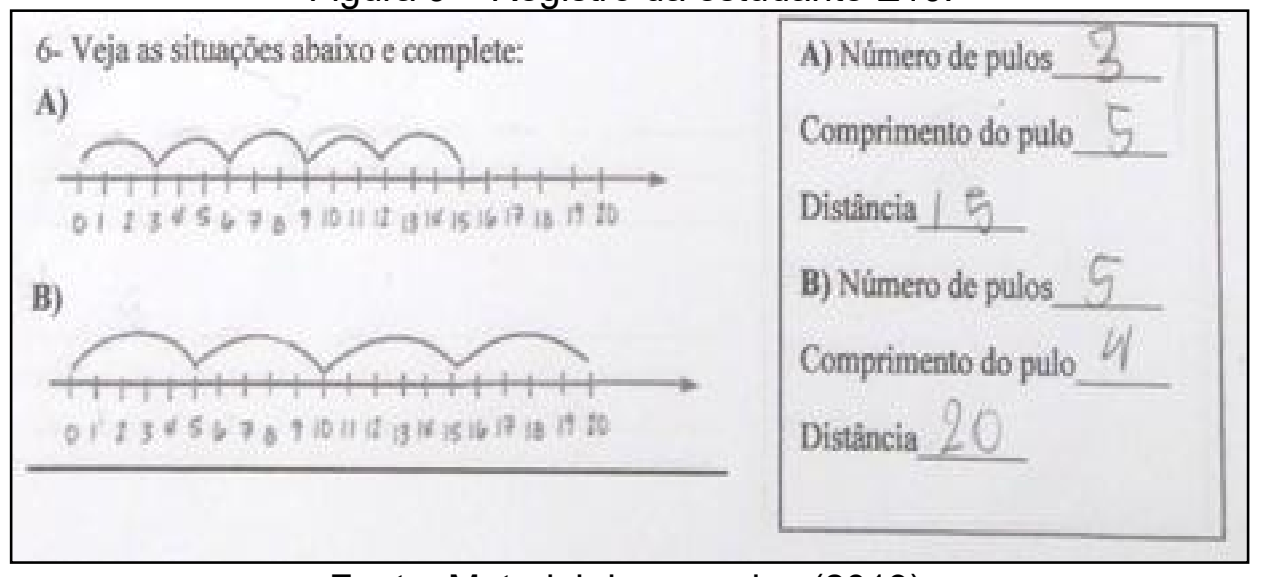

Fonte: Material da pesquisa (2019).

\section{Discutindo a situação e tirando proveito da experiência}

$\mathrm{Na}$ atividade apresentada, o objetivo foi trabalhar a multiplicação como adição de parcelas iguais de números naturais por meio de representações gráficas em uma semirreta numérica, de modo que os estudantes pudessem predizer onde a bota pararia com base nos números sorteados. O assunto não era novo para os estudantes, mas muitas dificuldades persistiam e a atividade poderia auxiliar na compreensão propriamente da operação que se realizava.

Conseguimos observar que, durante a atividade, os estudantes perceberam que a alteração na ordem dos fatores em uma das jogadas não alteraria o resultado, concluindo então 
que a ordem na multiplicação não alteraria o produto, o que foi verificado com a realização dos pulos. Nesse sentido, foi importante evidenciar que mesmo sem a alteração do resultado pela mudança da ordem dos fatores, a situação tinha sua natureza alterada. Isso é reforçado por Ramos (2009), ao indicar que não podemos dizer que a ordem dos fatores não faz diferença, mas sim, mostrar que as situações são diferentes, mesmo com resultados iguais.

A autora esclarece que a multiplicação com casos reais constitui uma ação, na qual utilizamos a linguagem matemática, em que devemos identificar e registrar o significado de cada número presente na situação. A Matemática na vida nos mostra situações em que as regras ficam em segundo plano e, em muitas vezes, desaparecem, sendo que ainda assim a solução é encontrada, o que denota a compreensão a partir da aplicação do conhecimento. Entretanto, "se represento concretamente uma multiplicação que vejo no dia a dia, e se percebo os significados de cada número, noto que quando inverto os números a situação se transforma" (RAMOS, 2009, p. 82).

Diante disso, é reforçada a importância de contextualizar o que ensinamos, no sentido de produzir significado para os estudantes e poder discutir situações reais. A partir do exemplo estudado, reforçar que a ordem dos fatores não altera o resultado sem atentar-se para a mudança da situação com relação à natureza dos números, reduz a potencialidade e o significado da multiplicação.

Com relação aos registros dos pulos, percebemos que foram poucos os estudantes que tiveram dificuldade quando não observaram os intervalos que deveriam ser respeitados para justificar o resultado da multiplicação sorteada nas fichas e, para isso, era necessária atenção especial ao zero, pois ele era o ponto de partida, bem como a igualdade do tamanho dos pulos.

Em relação à discussão do zero, levando a indagações sobre sua posição no quadro de ordem dos números, foi também possível perceber uma função de ocupar (resguardar) um valor posicional, o que facilitou muito a representação e, principalmente, as operações (CENTURIÓN, 1994). Isso ressalta a importância de se observar que a posição inicial, o zero, permite que o primeiro pulo acabe exatamente no número que representa o tamanho do pulo, bem como que todos os outros pulos realizados a partir deste terão como resultado os múltiplos do tamanho do pulo.

Com relação ao momento de exploração do jogo "A bota de muitas léguas", de acordo com os registros realizados pelos estudantes, não observamos dificuldades nos itens de um a quatro da atividade. Eles conseguiram compreender o que era solicitado e verbalizaram com segurança as respostas, o que facilitou a identificação da equipe vencedora por todos mais rapidamente. As repostas para o item cinco foram construídas coletivamente, em sala de aula, a partir das propostas dos estudantes.

Destacamos, nessa atividade, a importância do diálogo estabelecido na turma, conforme um dos objetivos iniciais. Os estudantes conversavam entre si e apresentavam suas sugestões, 
registradas no quadro com pincéis coloridos para marcar o que era distância e o que era pulo. A importância da participação dos estudantes, com base na representação de suas hipóteses, foi confirmada ao notar seu empenho para obter o resultado correto ou compreender as situações em que erravam.

\section{Considerações finais}

Constituímos um ambiente de aprendizagem, de acordo com a proposta de Nacarato, Mengali e Passos (2011), no qual realizamos atividades matemáticas permeadas pela produção do diálogo, da leitura e da escrita, em que a comunicação e a produção de significados são elementos primordiais. A atividade também mostrou grande potencial em permitir aos estudantes uma melhor compreensão da operação multiplicação com números naturais e a diferença entre contagem e medida.

No seguimento das tarefas, após o jogo, para favorecer a busca pela compreensão dos problemas e demais atividades, propusemos o trabalho em duplas/grupos e constatamos que práticas como essa enriquecem as experiências vividas em sala de aula e estimulam os estudantes na busca por soluções. O desenvolvimento do jogo, bem como a posterior análise das interações nos evidencia que quando os estudantes têm a oportunidade de compartilhar saberes e experiências, o aprendizado ocorre de forma mais significativa.

Apontamos, como possibilidades de continuidade das aulas, o trabalho com as retas numéricas, com o sistema métrico decimal e, também, a discussão acerca da invenção e do uso do zero. Também é possível trabalhar os múltiplos e a divisão com essa atividade. Nos cadernos do PNAIC há indicações de como fazê-lo, a partir da utilização de retas e fichas. Além disso, propostas semelhantes poderiam ser elaboradas e desenvolvidas em relação a ideia de multiplicação a partir do raciocínio combinatório, da configuração retangular e da proporcionalidade. O conjunto de todas estas abordagens levaria a uma compreensão mais ampla e profunda do conceito de multiplicação e dos números por parte dos estudantes.

Dessa maneira, mesmo nos referindo à multiplicação como adição de parcelas iguais, percebemos, tanto por meio dos estudos quanto da prática, que multiplicar constitui um raciocínio diferente de somar, uma vez que, na ideia aditiva da multiplicação, a natureza dos números é distinta (RAMOS, 2009). Portanto, a atividade proposta potencializou o sentido da multiplicação, tanto no aspecto aditivo quanto em suas características, ou seja, o trabalho mostrou que a interação proporcionada pelo jogo leva a uma melhor compreensão da multiplicação como soma de parcelas iguais, bem como ao fato de que a comutatividade estaria atrelada a uma mudança na situação apresentada. 


\section{Referências}

BIGODE, A. J. L.; FRANT, J. B. Multiplicação: ideias e conceitos - representações que ajudam a entender as ideias multiplicativas. In: BIGODE, Antônio José Lopes; FRANT, J. B. Matemática: soluções para dez desafios do professor. $1^{\circ}$ ao $3^{\circ}$ ano do Ensino Fundamental. 1. ed. São Paulo: Ática Educadores, 2011.

BIGODE, A. J. L.; GIMENEZ, J. Os significados dos números e das operações. In: BIGODE, Antônio José Lopes; GIMENEZ, Joaquin. Metodologia para o ensino de Aritmética: competência numérica no cotidiano. São Paulo: FTD, 2009.

BRASIL. Ministério da Educação. Secretaria de Educação Básica. Pacto Nacional pela Alfabetização na Idade Certa: Jogos na Alfabetização Matemática. Brasília: MEC/SEB, 2014.

BRASIL. Ministério da Educação. Secretaria de Educação Básica. Pró-Letramento: programa de formação continuada de professores dos anos/séries iniciais do Ensino Fundamental - Matemática. Brasília: MEC/SEB, 2007.

CARAÇA, Bento de Jesus. O problema da contagem. In: CARAÇA, Bento de Jesus. Conceitos Fundamentais da Matemática. Lisboa: Gradiva, 1998.

CARRAHER, T. N.; CAMPOS, T. M. M.; MAGINA, S.; BRYANT, P. As estruturas multiplicativas: avaliando e promovendo o desenvolvimento dos conceitos de multiplicação e divisão em sala de aula. In: CARRAHER, T. N.; CAMPOS, T. M. M.; MAGINA, S.; BRYANT, P. Introdução à Educação Matemática: os números e as operações numéricas. São Paulo: Cortez, 2005.

CARRAHER, T. N. O desenvolvimento mental e o sistema numérico decimal. In: CARRAHER, T. N. (Org.). Aprender pensando: contribuições da psicologia cognitiva para a educação. Petrópolis: Vozes, 1994.

CAVALCANTI, C. T. Diferentes formas de resolver problemas. In. SMOLE, K. S.; DINIZ, M. I. (Orgs.). Ler, escrever e resolver problemas: habilidades básicas para aprender Matemática. Porto Alegre: Artmed, 2001.

CENTURIÓN, M. Números e operações: conteúdo e metodologia da Matemática. São Paulo: Editora Scipione, 1994.

CONTI, K. C; LONGO, C. A. C. Resolver problemas e pensar a Matemática. In: CONTI, K. C.; LONGO, C. A. C.(Orgs.). Resolver problemas e pensar a matemática. Campinas, SP: Mercado das Letras, 2017.

LOPES, L. P. da M. O novo ethos dos letramentos digitais: modos de construir sentido, revolução das relações e performances identitárias fluidas. In: SIGNORINI, I.; FIAD, R. S. Ensino de língua: das reformas, das inquietações e dos desafios. Belo Horizonte: Editora UFMG, 2012.

MOREIRA, P. C.; DAVID, M. M. M. S. O conhecimento sobre os números e a prática docente na escola básica. In: MOREIRA, P. C.; DAVID, M. M. M. S. A formação matemática do professor: licenciatura e prática docente escolar. Belo Horizonte: Autêntica, 2007.

NACARATO, A. M.; MENGALI, B. L. da S.; PASSOS, C. L. B. A matemática nos anos iniciais do Ensino Fundamental: tecendo fios do ensinar e do aprender. Belo Horizonte: Autêntica Editora, 2011.

PENTEADO, H. D.; GARRIDO, E. (Orgs.). Pesquisa-ensino: A comunicação escolar na formação do professor. São Paulo: Paulinas, 2010. 
RAMOS, L. F. A construção conceitual das operações. In: RAMOS, L. F. Conversas sobre números, ações e operações: uma proposta criativa para o ensino da Matemática nos primeiros anos. São Paulo: Ática, 2009.

SMOLE, K. C. S.; DINIZ, M. I. Ler e aprender Matemática. In: SMOLE, K. C. S.; DINIZ, M. I. (Orgs.). Ler, escrever e resolver problemas: habilidades básicas para aprender Matemática. Porto Alegre: Artmed, 2001. 